\title{
molecules
}

ISSN 1420-3049

www.mdpi.com/journal/molecules

Article

\section{The Effect of Alkali and Ce(III) Ions on the Response Properties of Benzoxazine Supramolecules Prepared via Molecular Assembly}

Attaphon Kaewvilai ${ }^{1}$, Sawittree Rujitanapanich ${ }^{2}$, Worawat Wattanathana ${ }^{3}$, Chatchai Veranitisagul ${ }^{4}$, Songwut Suramitr ${ }^{3}$, Nattamon Koonsaeng ${ }^{3}$ and Apirat Laobuthee ${ }^{1,5, *}$

1 Department of Materials Engineering, Faculty of Engineering, Kasetsart University, Bangkok 10900, Thailand; E-Mail: kaewvilai@hotmail.com

2 Chemistry Program, Faculty of Science and Technology, Phranakhon Rajabhat University, Bangkok 10220, Thailand; E-Mail: sawittree_rj@yahoo.com

3 Department of Chemistry, Faculty of Science, Kasetsart University, Bangkok 10900, Thailand; E-Mails:w_worawat@hotmail.com (W.W.); fsciswsm@ku.ac.th (S.S.); fscinmk@ku.ac.th (N.K.)

Department of Materials and Metallurgical Engineering, Faculty of Engineering,

Rajamangala University of Technology Thanyaburi, Pathumthani 12110, Thailand;

E-Mail: veranitisagul.c@gmail.com

5 Center of Advanced Studies in Industrial Technology, Faculty of Engineering,

Kasetsart University, Bangkok 10900, Thailand

* Authors to whom correspondence should be addressed; E-Mails: fengapl@ku.ac.th;

Tel.: +66-2-942-855-5 ext 2132; Fax: +66-2-955-181-1.

Received: 8 October 2011; in revised form: 16 December 2011 / Accepted: 1 January 2012 /

Published: 5 January 2012

Abstract: A series of benzoxazine monomer supramolecules with different substituted groups on their benzene ring was prepared with a Mannich reaction and characterized by FTIR, ${ }^{1} \mathrm{H}-\mathrm{NMR}$ and MS. The obtained products were 3,4-dihydro-3-(2'-hydroxyethylene)6-methyl-2H-benzoxazine (BM1), 3,4-dihydro-3-(2'-hydroxyethylene)-6-ethyl-2H-benzoxazine (BM2), and 3,4-dihydro-3-(2'-hydroxyethylene)-6-methoxy-2H-benzoxazine (BM3). The efficiency of alkali metal ion extraction from the products was determined with Pedersen's technique, while the complexation of the Ce(III) ion was confirmed by the Job's and the mole ratio methods. The evidence of complex formation between benzoxazine monomers and $\mathrm{Ce}$ (III) ions was obtained with FTIR and a computational simulation. Single phase ceria $\left(\mathrm{CeO}_{2}\right)$ as observed with XRD was successfully prepared by calcinating the $\mathrm{Ce}(\mathrm{III})$-benzoxazine monomer complexes at $600{ }^{\circ} \mathrm{C}$ for $2 \mathrm{~h}$. In addition, the 
geometry of the ceria nanoparticles confirmed by TEM is spherical, with an average diameter of 10-20 $\mathrm{nm}$.

Keywords: benzoxazine monomers; supramolecules; Pedersen's technique; complexation; molecular assembly

\section{Introduction}

Supramolecules are known as specific structures, usually in two- or three-dimensions, obtained by linking a series of molecules. Their properties are completely different from the individual components [1-5]. The molecular interactions between supramolecules and guests to form host-guest compounds or inclusion compounds are induced by non-covalent interactions or secondary forces, such as van der Waals, dipole-dipole interaction, hydrogen bonding, etc [1-5]. Therefore, novel supramolecules with specific functional groups for the desired properties have been designed and proposed as both molecular assembly and cyclic structures [1-5].

Chirachanchai et al. originally proposed some novel supramolecules, benzoxazine oligomers, as ion extraction materials [6]. According to this idea, the guest-responsive ability of the benzoxazines resembled to repeating unit of calixarenes and acyclic para-substituted phenol-formaldehyde oligomers was investigated [6].

To understand the properties of benzoxazine supramolecules, systematical studies of the inclusion phenomena of a series of benzoxazine molecules have been performed [6-13]. As expected from the molecular designs, $p$-substituted benzoxazine monomers have been used as a starting materials in ring opening reactions to obtain novel benzoxazine molecules of either the cyclic or non-cyclic type [6-13]. Although since 1944 benzoxazine monomers have been simply prepared by a Mannich reaction from phenol, formaldehyde and primary amine sa originally proposed by Holly and Cope [14], there were few studies about benzoxazine monomers as supramolecules [15]. Based on the molecular structures of the benzoxazine monomers, it turned out to be an interesting objective to determine the metal ion responsive properties of the $p$-substituted benzoxazine monomers. The aim of this work was, therefore, to prepare benzoxazine monomers with a Mannich reaction and to investigate their ion extraction abilities with alkali metal ions with Pedersen's technique [16,17].

In our related work, the complex method has been focused to prepare highly pure and homogeneous ceria for applications in the solid support catalyst for electrolytes for solid oxide fuel cells, methane steam reforming and hydrogenation [18-20]. In this work, the benzoxazine monomers used as novel ligands for rare earth ions such as Ce(III) were also qualitatively and quantitatively studied by the Job's and molar ratio methods. The evidence of the complex formation between benzoxazine monomers and $\mathrm{Ce}$ (III) ions was clarified with FTIR and a computational simulation. In addition, the obtained complexes were further applied as precursors for the preparation of ceria powder. 


\section{Results and Discussion}

\subsection{Preparation of Monomers by the Mannich Reaction}

Benzoxazine monomers (3,4-Dihydro-3-(2'-hydroxyethylene)-6-alkyl-2H-benzoxazines, BM) were prepared by a Mannich reaction as shown in Scheme 1.

Scheme 1. Preparation of benzoxazine monomers by Mannich Reaction.

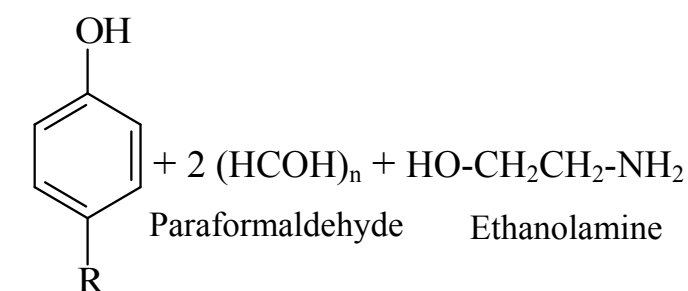

Phenol derivatives<smiles>[R]c1ccc2c(c1)CN(CCO)CO2</smiles>

3,4-dihydro-3-(2'-hydroxyethylene)6-alkyl-2H-benzoxazines (BM)

$$
\mathrm{R}=-\mathrm{CH}_{3}(\mathbf{B M 1}),-\mathrm{C}_{2} \mathrm{H}_{5}(\mathbf{B M}) \text {, and }-\mathrm{OCH}_{3}(\mathbf{B M 3})
$$

To confirm the successful preparation of benzoxazine monomers by a Mannich reaction, the reactions were examined by FTIR, ${ }^{1} \mathrm{H}-\mathrm{NMR}$ and MS. Typical results as exemplified by BM1 were as follows: as shown in Figure 1, the FTIR spectrum of BM1 shows a broad peak around 3600-3200 cm ${ }^{-1}$ due to the alcohol hydroxyl group. There are also three characteristic peaks for BM1 found at 1500, 1226, and $1126 \mathrm{~cm}^{-1}$ belonging to trisubstituted benzene, C-N stretching, and C-O-C stretching, respectively.

Figure 1. FTIR spectrum of BM1.

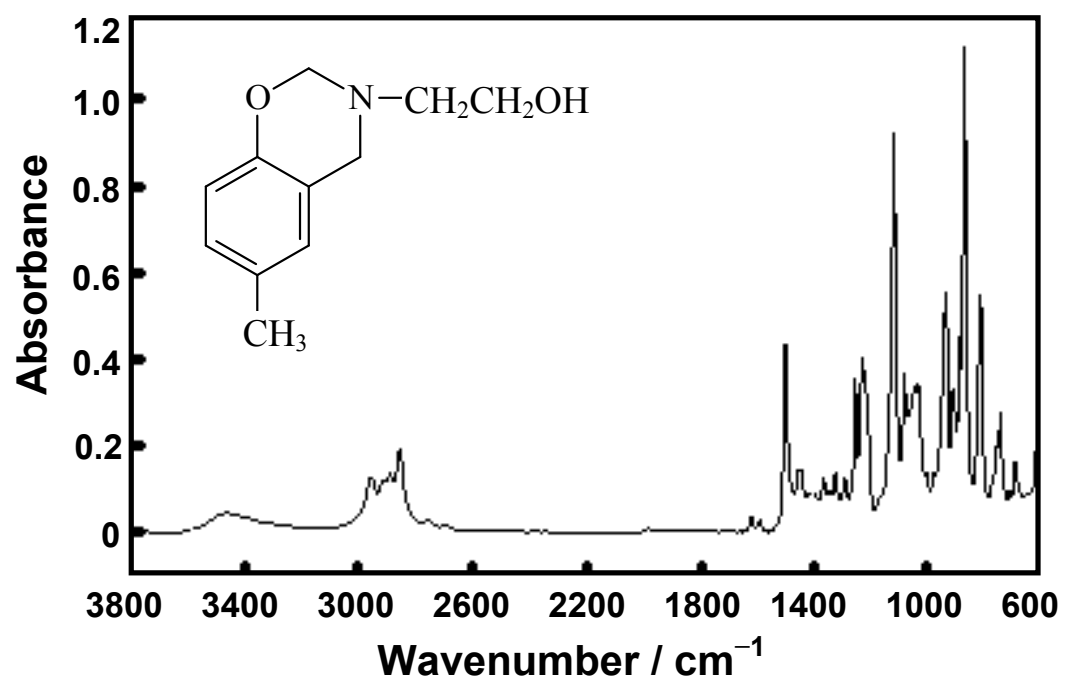

The ${ }^{1} \mathrm{H}-\mathrm{NMR}$ spectrum of BM1 (Figure 2) exhibits two characteristic peaks corresponding to the two methylene groups in the oxazine ring, specifically at $\delta_{\mathrm{H}}=4.33 \mathrm{ppm}$ for the one between benzene and nitrogen ( $\left.\mathrm{N}-\mathbf{C H}_{2}-\mathrm{Ar}\right)$ and at $\delta_{\mathrm{H}}=4.83 \mathrm{ppm}$ for the other between nitrogen and oxygen $\left(\mathrm{O}-\mathbf{C} \mathbf{H}_{2}-\mathrm{N}\right)$. 
Figure 2. ${ }^{1} \mathrm{H}-\mathrm{NMR}$ spectrum of BM1.

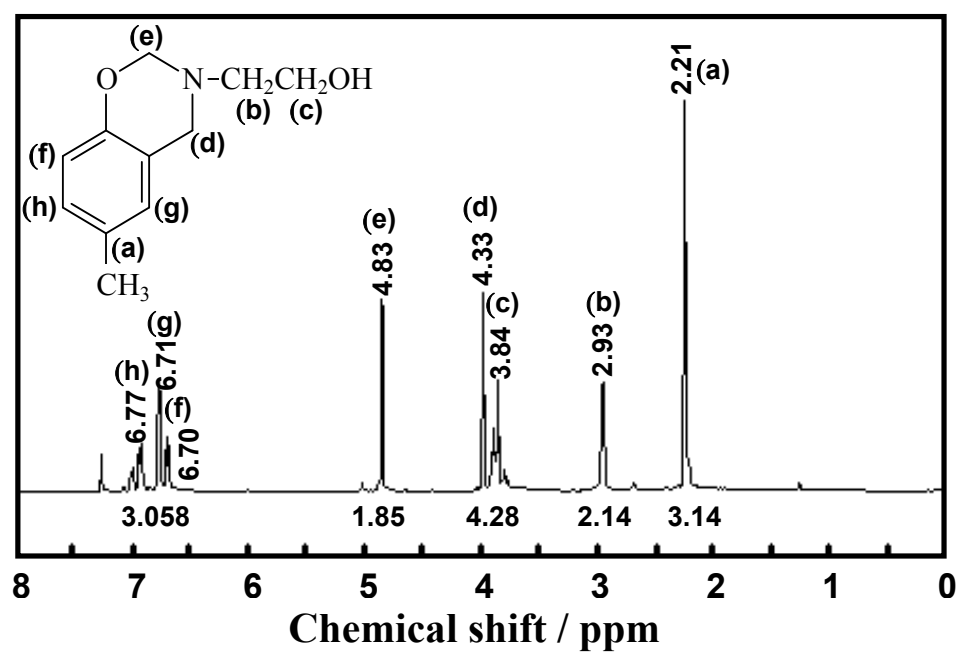

In addition, the chemical shifts of the methylene protons of the substituted group at nitrogen were found at $2.93 \mathrm{ppm}$ (adjacent to nitrogen, $\mathrm{N}-\mathbf{C H}_{2}-\mathrm{CH}_{2}-\mathrm{OH}$ ) and at $3.84 \mathrm{ppm}$ (adjacent to the hydroxyl group, $\left.\mathrm{N}-\mathrm{CH}_{2}-\mathbf{C H}_{2}-\mathrm{OH}\right)$.

A soft ionization mass spectrometer was used to determine the molecular weight of BM1 from the molecular ion peak. The calculated molecular weight of BM1 was found to be 193. Figure 3 shows only one peak occurring at $\mathrm{m} / \mathrm{z}=194$, which was assigned to the protonated peak $(\mathrm{M}+1)$ of BM1. By expanding the chemical shift scale, a small satellite peak due to ${ }^{13} \mathrm{C}$ atoms in the BM1molecule was found at $\mathrm{m} / \mathrm{z}=195$ (Figure 3) since the percent abundance of ${ }^{13} \mathrm{C}$ atoms is found to be $1.1 \%$ of all carbon atoms. From all the characterization results, it can be concluded that the product of $p$-cresol, paraformaldehyde, and ethanolamine from the Mannich reaction is 3,4-dihydro-3-(2'-hydroxy ethylene)-6-methyl-2H-benzoxazine (BM1).

Figure 3. Mass spectrum of BM1.

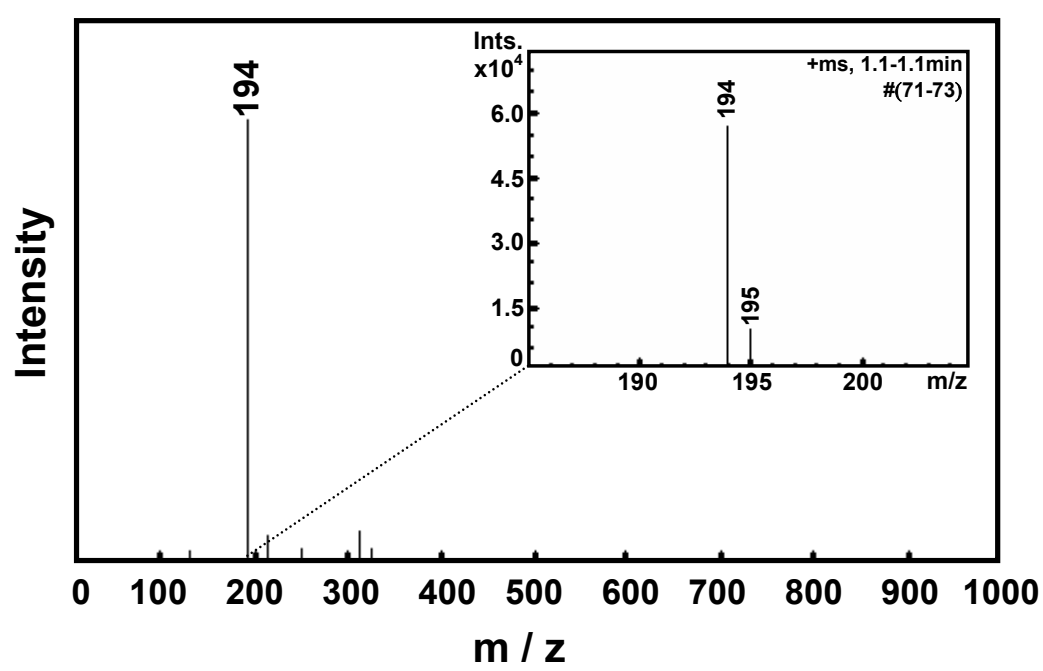

By similar characterizations, the products, BM2 and BM3, were identified as 3,4-dihydro-3-(2'hydroxyethylene)-6-ethyl-2H-benzoxazine and 3,4-dihydro-3-(2'-hydroxy ethylene)-6-methoxy-2H- 
benzoxazine, respectively. It should be noted that the Mannich reaction gives the benzoxazine monomer as a single product, indicating that the reaction is a simple and effective reaction for monomer preparation. The characterization of all products is summarized in the Experimental section and the molecular structures are shown in scheme 1.

\subsection{Liquid Extraction of Alkali Metal Ions}

To clarify the relationship between the structure of products (BM1, BM2, and BM3) and alkali metal ion extraction ability, the qualitative and quantitative analyses were performed using Pedersen's technique [16,17]. Figure 4 compares the absorption spectra of $\mathbf{B M 1}, \mathrm{Na}^{+}$-picrate and the extracted $\mathrm{Na}^{+}$-BM1 complex in organic phase. On complexation, the aromatic $\pi \rightarrow \pi^{*}$ transition of BM1 $\left[\lambda_{\max }=288 \mathrm{~nm}\right.$, Figure 4(a) $]$ disappeared and the new absorption band $\left[\lambda_{\max }=376 \mathrm{~nm}\right.$, Figure 4(c)] which was slightly shifted from that of $\mathrm{Na}^{+}$-picrate $\left[\lambda_{\max }=355 \mathrm{~nm}\right.$, Figure $\left.4(\mathrm{~b})\right]$ was observed. This implied that $\mathrm{Na}^{+}$ion diffused from aqueous $\mathrm{Na}^{+}$-picrate to form $\mathrm{Na}^{+}-\mathbf{B M 1}$ complex in $\mathrm{CH}_{2} \mathrm{Cl}_{2}$ phase.

Figure 4. UV-Vis absorption spectra of (a) BM1, (b) $\mathrm{Na}^{+}$-picrate, and (c) complex of BM1 and $\mathrm{Na}^{+}$ions.

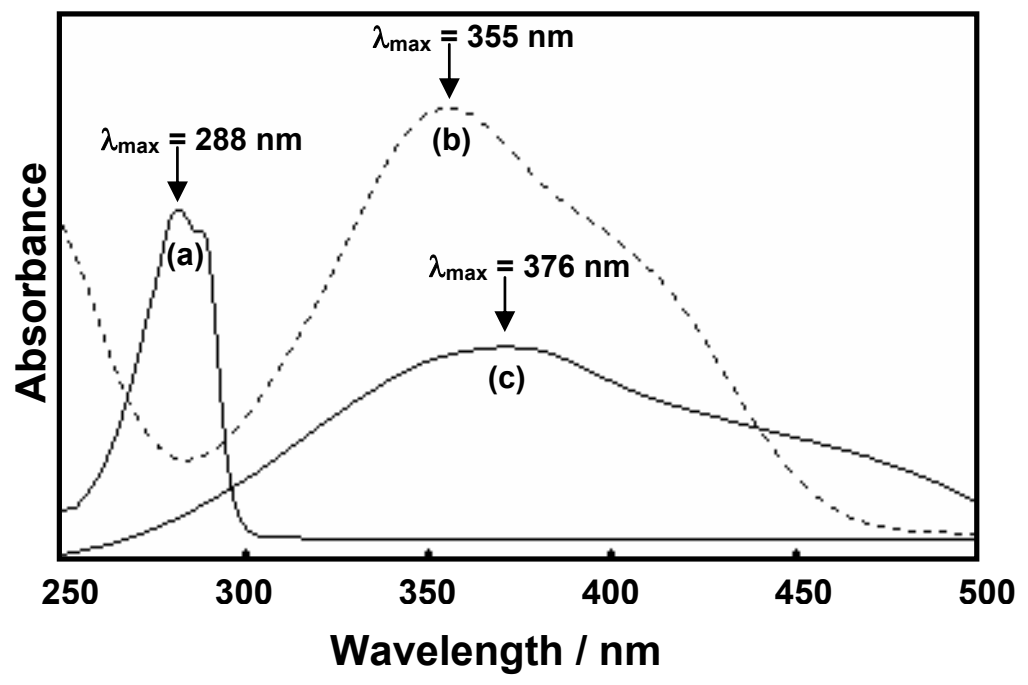

The maximum absorption bands of all benzoxazine derivatives (BM1, BM2 and BM3) and their alkali metal ion picrate as well as the corresponding metal benzoxazine complexes are similar and summarized in Table 1.

Table 1. Maximum absorption peaks of benzoxazine derivatives, alkali - picrates, and alkali metal ion - benzoxazine complexes.

\begin{tabular}{|c|c|c|c|c|c|c|}
\hline \multirow{2}{*}{$\begin{array}{c}\text { Benzoxazine } \\
\text { derivatives }\end{array}$} & $\lambda_{\max }(\mathbf{n m})$ & $\mathbf{M}^{+}$-picrates & \multirow{2}{*}{$\boldsymbol{\lambda}_{\max }(\mathbf{n m})$} & \multicolumn{3}{|c|}{$\begin{array}{c}\mathbf{M}^{+} \text {-benzoxazine derivative } \\
\text { complexes, } \boldsymbol{\lambda}_{\max }(\mathbf{n m})\end{array}$} \\
\cline { 4 - 6 } & & & & $\mathbf{N a}^{+}$ & $\mathbf{K}^{+}$ & $\mathbf{C s}^{+}$ \\
\hline BM1 & 288 & $\mathbf{N a}^{+}$-picrate & 355 & 376 & 432 & 422 \\
$\mathbf{B M 2}$ & 288 & $\mathbf{K}^{+}$-picrate & 355 & 378 & 435 & 430 \\
$\mathbf{B M 3}$ & 298 & $\mathbf{C s}^{+}$-picrate & 355 & 396 & 450 & 445 \\
\hline
\end{tabular}


With increasing concentrations of BM1, BM2, and BM3, the extraction percentage of all alkali metal ions gradually increases, as presented in Figure 5. The dependence of the extraction ability on benzoxazine monomer concentrations exhibits supramolecular properties like the benzoxazine dimers reported elsewhere [10]. For all concentrations, the extraction ability is BM2 $>$ BM3 $>$ BM1. This implies that substituent at the phenyl ring of benzoxazine monomer is responsible for the formation of the supramolecular assembly to form the space available to entrap the alkali metal ions for complexation.

Figure 5. Extraction percentages of $7.0 \times 10^{-5} \mathrm{M}$ alkali-picrate (a) $\mathrm{Na}^{+}$- picrate, (b) $\mathrm{K}^{+}$-picrate, and (c) $\mathrm{Cs}^{+}$-picrate by various concentrations of benzoxazine derivatives in $\mathrm{CH}_{2} \mathrm{Cl}_{2}$ at $25^{\circ} \mathrm{C}$.
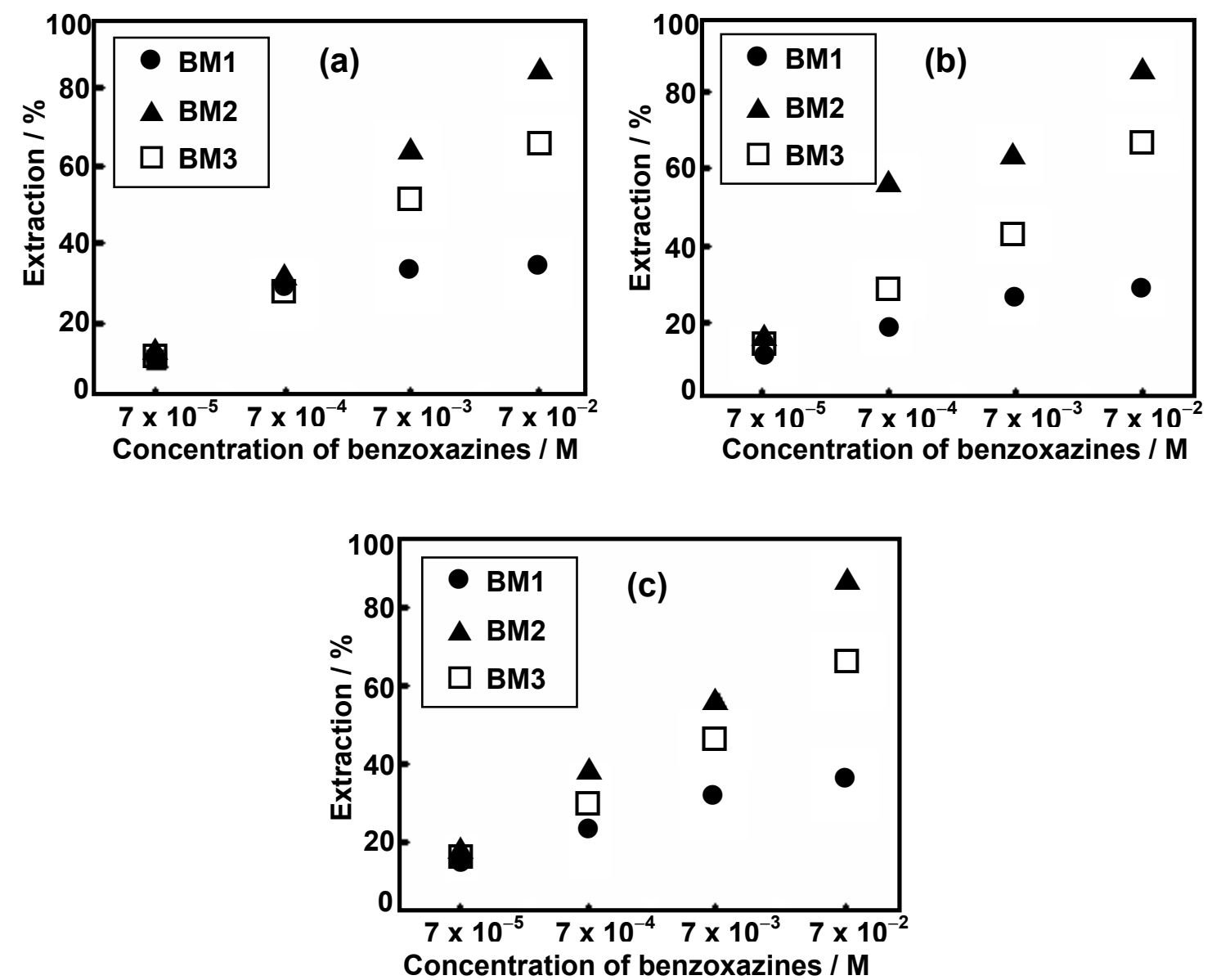

At the highest concentration of benzoxazine $\left(7.0 \times 10^{-2} \mathrm{M}\right)$, the ion extraction $\%$ of the individual benzoxazines for each alkali ion is not significantly different; approximately $30 \%, 80 \%, 60 \% \mathrm{of} \mathrm{Na}^{+}$, $\mathrm{K}^{+}, \mathrm{Cs}^{+}$were extracted by BM1, BM2 and BM3, respectively, as shown in Figure 6.

The highest efficiency of BM2 for different sizes of alkali metal ions demonstrated that the generated molecular assembly provides a space for entrapping alkali metal ions. In addition, the electron donating group, $-\mathrm{C}_{2} \mathrm{H}_{5}$ substituted at the para-position also enhanced the electrostatic interaction of guest $\left(\mathrm{Na}^{+}, \mathrm{K}^{+}, \mathrm{Cs}^{+}\right)$, consequently, alkali metal ions-BM2 host-guest compounds with high yield were formed. Observation of lower extraction via molecular assembly might be due to the electron withdrawal from the $-\mathrm{OCH}_{3}$ group of BM3. Additionally, the lowest extraction ability found 
for BM1 suggested a reduction of available space in the molecular assembly because of the least steric hindrance of substituent group $-\mathrm{CH}_{3}$ in BM1 compared to $-\mathrm{C}_{2} \mathrm{H}_{5}$ and $-\mathrm{OCH}_{3}$ in BM2 and BM3, respectively.

Figure 6. Extraction percentages of $7.0 \times 10^{-5} \mathrm{M}$ alkali metal ions by $7.0 \times 10^{-2} \mathrm{M}$ benzoxazine derivatives in $\mathrm{CH}_{2} \mathrm{Cl}_{2}$ at $25^{\circ} \mathrm{C}$.

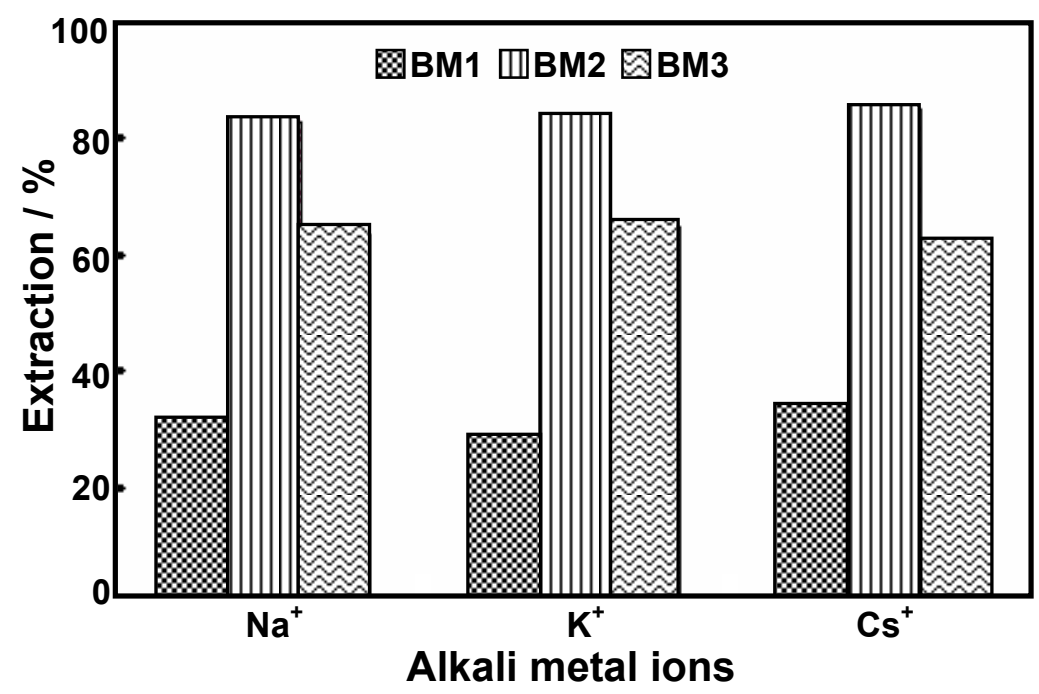

\subsection{Complexation of Benzoxazine Monomers and Ce(III) Ion}

The complex formation between Ce(III) ion and benzoxazine monomers showed $\lambda_{\max }$ at 459,455 , and $470 \mathrm{~nm}$ for $\mathrm{Ce}(\mathrm{III})-\mathbf{B M 1}, \mathrm{Ce}(\mathrm{III})-\mathbf{B M 2}$, and $\mathrm{Ce}(\mathrm{III})-\mathbf{B M 3}$, respectively, and their absorption spectra are illustrated in Figure 7.

Figure 7. UV-Vis absorption spectra of complexes in ethanolic solution: $\mathrm{Ce}(\mathrm{III})-\mathbf{B M 1}$, (b) $\mathrm{Ce}(\mathrm{III})-\mathbf{B M} 2$, and (c) $\mathrm{Ce}(\mathrm{III})-\mathbf{B M 3}$.

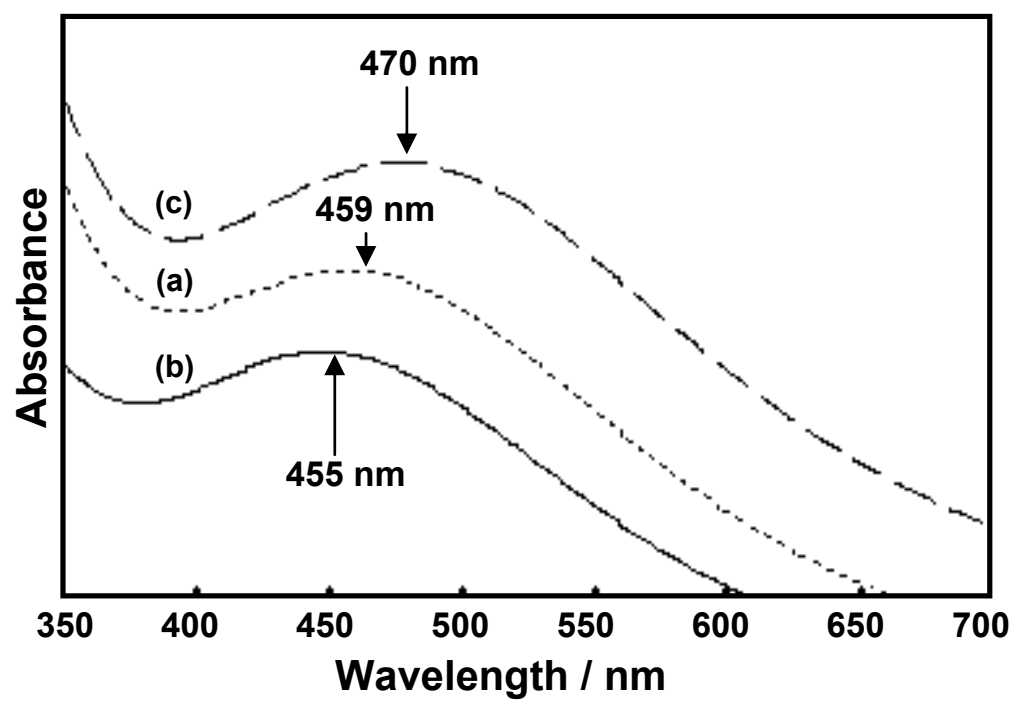

Figure 8 shows the molar ratios and Job's plots of the complexes in ethanol. 
Figure 8. (a) Molar ratio plot and (b) Job's plot of Ce(III)-benzoxazine monomer complexes in ethanolic solution.
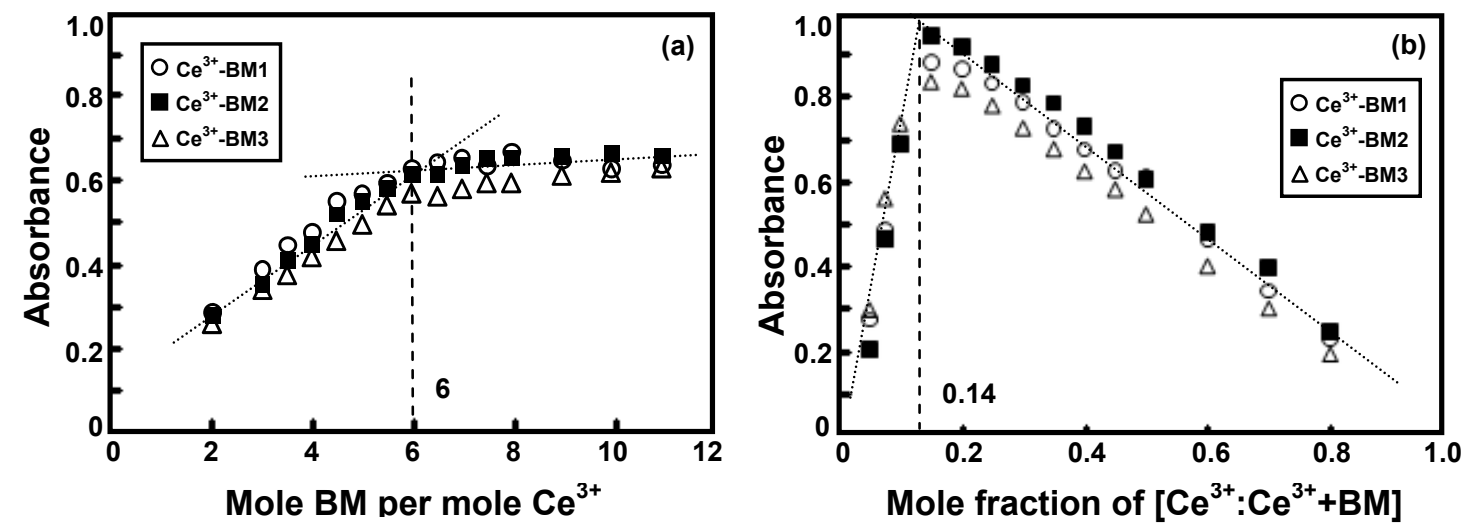

The results obtained from the molar ratio and the Job's methods are clearly in good agreement with Ce(III) : benzoxazine monomers (BM1-BM3) ratios of 1:6. This shows that the para-substituted groups on the molecular structure of benzoxazine monomers did not effect the $\mathrm{Ce}$ (III)-ligand ratio.

To clarify the complex formation evidence, the FTIR spectrum of BM1 [Figure 9(a)] and that of the complex between BM1 and $\mathrm{Ce}(\mathrm{III})$ ion [Figure 9(b)] were compared. It was found that the characteristic peaks of BM1 [oxazine ring, C-N stretching and aromatic ether (Ar-O-C)] were shifted from 1500,1252 and $1027 \mathrm{~cm}^{-1}$ to 1467,1266 and $1052 \mathrm{~cm}^{-1}$, respectively. This implied that the benzoxazine monomer might form a complex with $\mathrm{Ce}$ (III) ion by using an oxygen or nitrogen atom in the oxazine ring as coordination atoms. However, the hydroxyl peak in the range of $3600-3200 \mathrm{~cm}^{-1}$ was unchanged. Since the complex is (unhygroscopic) dried by anhydrous $\mathrm{Na}_{2} \mathrm{SO}_{4}$ and vacuum evaporated, this might be due to the fact that the hydroxyl group of BM1 was not involved in the complex formation. This evidence was also confirmed by the other related works, since benzoxazine monomers without a hydroxyl group can form complexes with $\mathrm{Ce}(\mathrm{III})$ ion.

Figure 9. FTIR spectra of (a) BM1 and (b) Ce(III)-BM1 complexes.

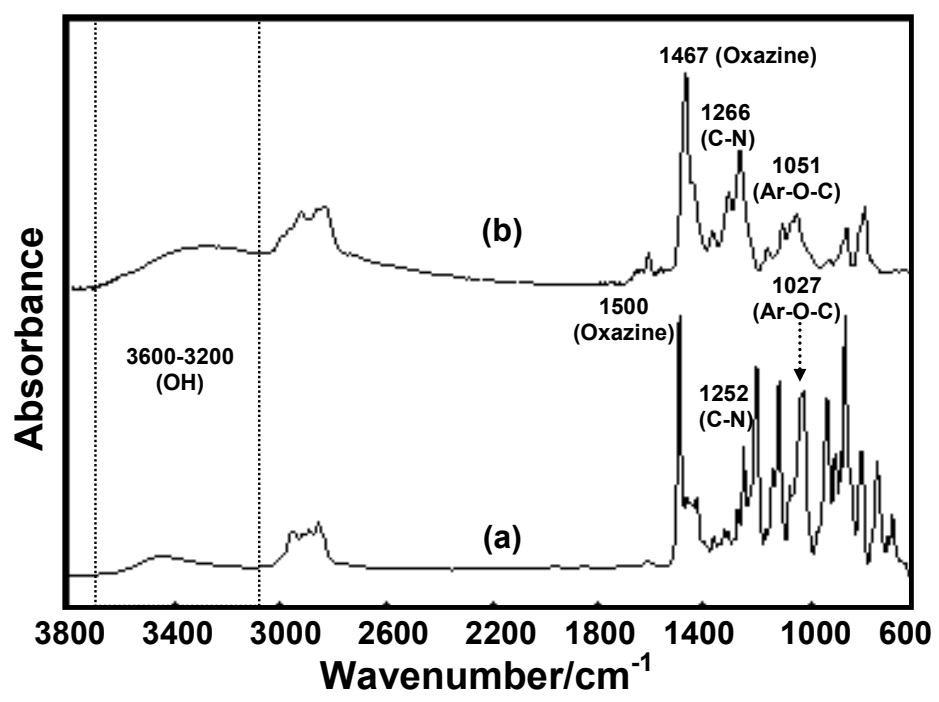




\subsection{Computational Simulation}

To propose the possible structure of Ce(III)-BM1 complex, a computational simulation was studied. By using electrostatic interaction of $\mathrm{Ce}(\mathrm{III})$ with the electron donor atom, $\mathrm{O}$ or $\mathrm{N}$ of BM1 ligand, the lowest energy for equilibration was found with in $60 \mathrm{ps}$ simulation time, as shown in Figure 10. The total energy profile indicated equilibration of only $10 \mathrm{ps}$.

Figure 10. Graph of potential energy $v s$. time during geometry optimization.

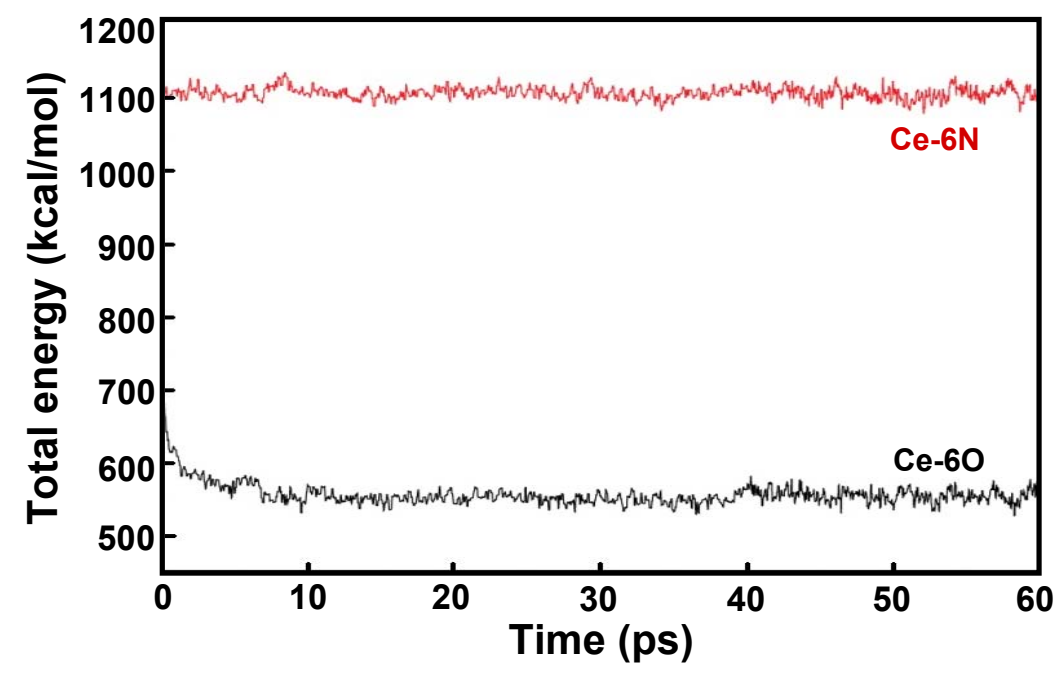

The structure of the cerium complex binding with the $\mathrm{O}$ position was of lower energy than binding to the $\mathrm{N}$-atom (Figure 11). It is indicated that the $\mathrm{Ce}(\mathrm{III})$ ion showed specific binding to the O-atom of the BM1 ligand along the octahedral structure during the optimization using MD simulations, Figure 11(a). As expected, the $\mathrm{Ce}(\mathrm{III})$ ion was attracted to the O-atom of the octahedral with a stable trajectory. This geometry proved that at room temperature $\mathrm{Ce}(\mathrm{III})$ ion specifically binds to the $\mathrm{O}$-atom of BM1 molecule in octahedral complex.

Figure 11. Orientation of (a) $\mathrm{Ce}-\mathrm{O}$ and (b) Ce-N complexes.

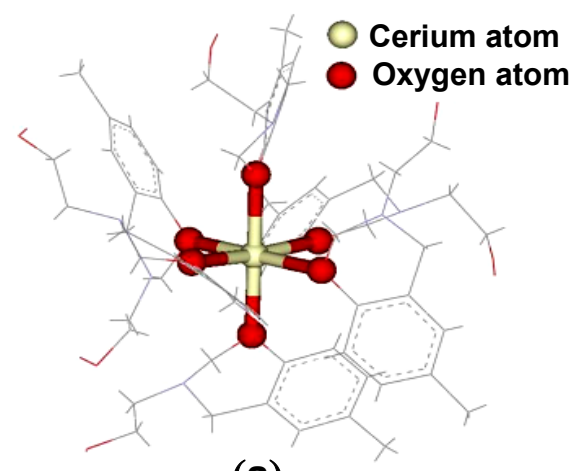

(a)

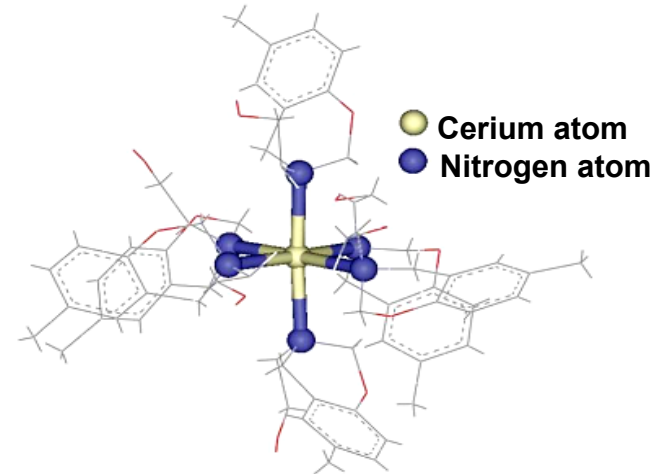

(b)

To recover the expensive Ce(III) ions after the complex formation study, the obtained $\mathrm{Ce}$ (III)-benzoxazine monomer complexes were collected, the solvent removed and then calcined at $600{ }^{\circ} \mathrm{C}$ for $2 \mathrm{~h}$ [19]. The XRD diffraction patterns of the calcined powders derived from all of the 
$\mathrm{Ce}(\mathrm{III})$-benzoxazine monomer complexes show the reflection peaks which are in agreement with the fluorite structure, $\mathrm{CeO}_{2}$ (JCPDS No. 34-0394), as shown in Figure 12. The crystallite size of the $\mathrm{CeO}_{2}$ produced showed no significant difference (Table 2).

Figure 12. XRD patterns of (a) JCPDS No. 34-0394 and ceria powder derived from Ce(III)-benzoxazine monomer complexes: (b) $\mathrm{Ce}(\mathrm{III})-\mathbf{B M 1}$, (c) $\mathrm{Ce}(\mathrm{III})-\mathbf{B M 2}$, and (d) $\mathrm{Ce}(\mathrm{III})-\mathbf{B M 3}$.

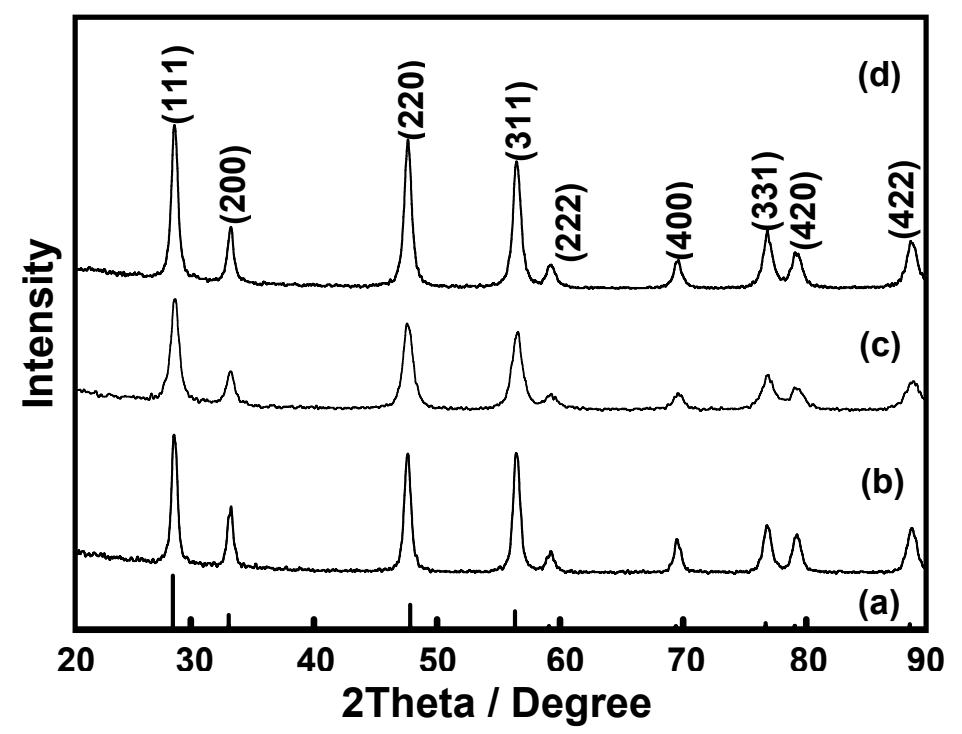

Table 2. The crystallite sizes of $\mathrm{CeO}_{2}$ determined by the application of the Scherrer equation.

\begin{tabular}{|c|c|c|c|}
\hline Ce(III)-benzoxazine monomer complexes & Ce(III)-BM1 & $\mathrm{Ce}(\mathrm{III})$-BM2 & $\mathrm{Ce}(\mathrm{III})$-BM3 \\
\hline Crystallite size (nm) & 16 & 11 & 14 \\
\hline
\end{tabular}

By measuring the particle size from TEM micrographs, most particles obtained from all complexes were found to be spherical, with an average diameter of 10-20 nm (Figure 13). In addition, the results also indicate that the type of benzoxazine monomer used does not affect the morphology and the particle size of the ceria.

Figure 13. TEM micrographs at $100 \mathrm{kv}$ of ceria nanoparticles derived from Ce(III)-benzoxazine complexes (a) Ce(III)-BM1 ( $\times 20.0 \mathrm{k}),($ b) $\mathrm{Ce}(\mathrm{III})-\mathbf{B M 2}(\times 24.0 \mathrm{k})$ and (c) $\mathrm{Ce}(\mathrm{III})-\mathbf{B M 3}(\times 25.0 \mathrm{k})$.
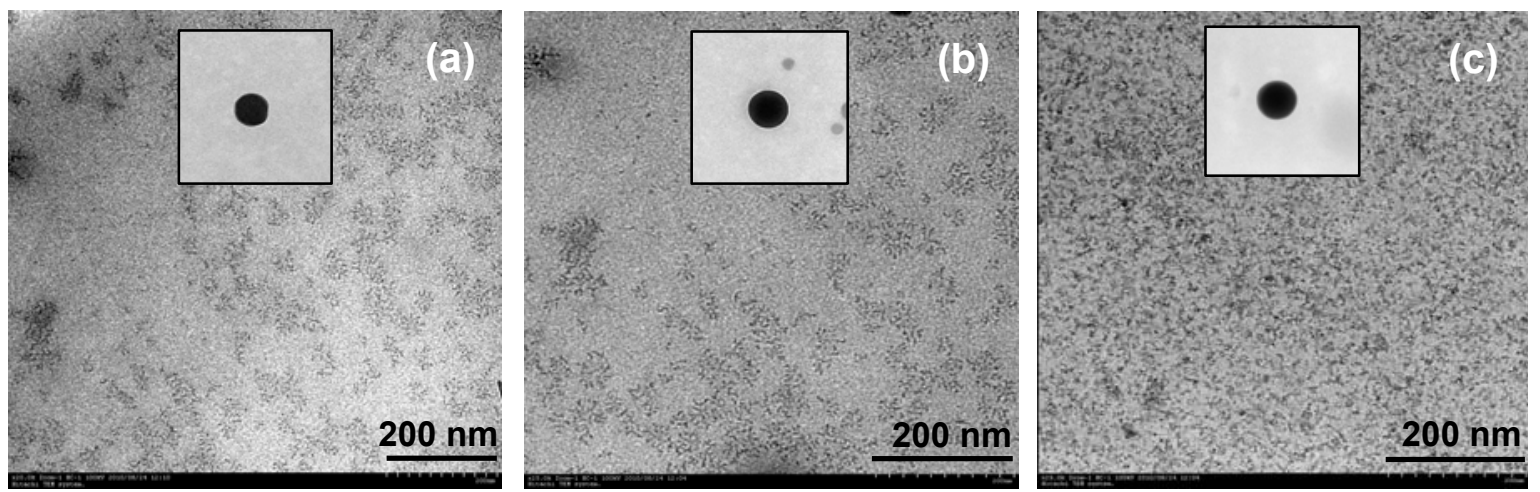


\section{Experimental}

\subsection{Chemicals}

Paraformaldehyde was obtained from Sigma (USA). 4-Methoxyphenol, 4-ethylphenol, $p$-cresol, ethanolamine, potassium hydroxide, cesium carbonate and sodium sulfate anhydrous were ordered from Fluka Chemicals (Buchs, Switzerland). Cerium(III) nitrate hexahydrate $\left[\mathrm{Ce}\left(\mathrm{NO}_{3}\right)_{3} \cdot 6 \mathrm{H}_{2} \mathrm{O}, 99.50 \%\right.$ purity] was bought from Acros Organics. Ethanol, iso-propanol, acetonitrile, sodium hydroxide, picric acid, and methylene chloride, diethylether were the products of Ajax Chemicals (Australia). All chemicals were analytical grade and used as received.

\subsection{Instruments}

The obtained products were characterized with a Fourier transform ${ }^{1} \mathrm{H}-\mathrm{NMR}$ spectrometer (Varian Mercury-400 spectrometer) with $\mathrm{CDCl}_{3}$ as a solvent. The infrared spectra were obtained from a Fourier transform infrared spectrophotometer (Bruker ALPHA FT-IR spectrometers) with 32 scans at a $4 \mathrm{~cm}^{-1}$ resolution. The mass spectra of products dissolved in methylene chloride were obtained on an ESI-MS instrument (Bruker Esquire mass spectrometer). The UV-Visible spectra and the absorption of all mixed solutions were measured with a Shimadzu UV-1700 spectrophotometer over a wavelength of 200 to $700 \mathrm{~nm}$.

The calcined powders were investigated by X-ray diffraction (XRD: a Bruker D8-Advance X-ray diffractrometer with $\mathrm{CuK}_{\alpha}$ radiation). Diffraction patterns were recorded over a range of $2 \theta$ angles from 20 to 90 degrees in a step-scanning mode $\left(0.02^{\circ}\right.$ steps with a step-counting time of $\left.2 \mathrm{sec}\right)$. The crystalline phase was identified from the Joint Committee on Powder Diffraction Standard (JCPDS) file No. 34-0394.

The crystallite size $\left(\mathrm{D}_{\mathrm{XRD}}\right)$ of the calcined powders was determined using the Scherrer equation: $\mathrm{D}=0.9 \lambda / \beta \cos \theta$, where $\lambda$ is the wavelength of the X-rays $(1.5406 \AA), \theta$ is the scattering angle of the main reflection (111), and $\beta$ is the corrected peak at full width at half-maximum (FWHM) intensity.

The morphology of the obtained ceria powders observed with a transmission electron microscope (TEM) was taken at an accelerating voltage current of $100.0 \mathrm{kV}$ by Hitachi H-7650 (Hitachi HighTechnology Corporation, Japan).

\subsection{Preparation of Monomers by the Mannich Reaction}

3,4-Dihydro-3-(2'-hydroxyethylene)-6-methyl-2H-benzoxazine (BM1) was prepared as shown in Scheme 1. Paraformaldehyde $(6.31 \mathrm{~g}, 210.0 \mathrm{mmol})$ was dissolved in dioxane $(50.0 \mathrm{~mL})$, followed by the addition of ethanolamine $(6.0 \mathrm{~mL}, 100.0 \mathrm{mmol})$ in dioxane $(10.0 \mathrm{~mL})$ and $p$-cresol $(10.8 \mathrm{~g}$, $100.0 \mathrm{mmol})$ in dioxane $(50.0 \mathrm{~mL})$. The mixture was stirred and allowed to reflux for $3 \mathrm{~h}$. The solution was then collected to remove dioxane by vacuum distillation. The yellow and sticky liquid phase obtained was dissolved in diethyl ether. The resulting solution was then extracted with $3 \mathrm{~N} \mathrm{NaOH}$ $(20 \mathrm{~mL})$ three times, followed by several water washes. The product was dried over anhydrous sodium sulfate and the solvent was removed to obtain a clear and yellow liquid product. Yield 75\%; clear and yellow liquid; $\mathrm{R}_{\mathrm{f}}=0.82\left(10 \% \mathrm{MeOH}\right.$ in $\left.\mathrm{CH}_{2} \mathrm{Cl}_{2}\right)$; FTIR (ATR, ZnSe, $\left.\mathrm{cm}^{-1}\right)$ : 3600-2900 (br, OH), 
2877 (s, CH), 1500 (oxazine ring), 1226 (s, CN), 1126 (s, CO), 1027 (s, Ar-O-C), 817 (b, CH); ${ }^{1} \mathrm{H}$ NMR (400 MHz, $\left.\mathrm{CDCl}_{3}, \mathrm{ppm}\right): \delta_{\mathrm{H}} 2.21\left(3 \mathrm{H}, \mathrm{s}, \mathrm{Ar}-\mathbf{C H}_{3}\right), 2.93\left(2 \mathrm{H}, \mathrm{t}, \mathbf{C H}_{2} \mathrm{CH}_{2} \mathrm{OH} J_{2}=3.11 \mathrm{~Hz}\right), 3.84$ $\left(2 \mathrm{H}, \mathrm{t}, \mathrm{CH}_{2} \mathbf{C H}_{2} \mathrm{OH} J_{2}=3.11 \mathrm{~Hz}\right), 4.33\left(2 \mathrm{H}, \mathrm{s}, \mathrm{Ar}-\mathbf{C H}_{2}-\mathrm{N}\right), 4.83\left(2 \mathrm{H}, \mathrm{s}, \mathrm{O}-\mathbf{C H}_{2}-\mathrm{N}\right), 6.70(\mathrm{H}, \mathrm{d}, \mathbf{A r}-\mathbf{H}$, $\left.J_{3}=2.34 \mathrm{~Hz}\right), 6.71$. (H, s, Ar-H), 6.77 (H, d, Ar-H, $\left.J_{3}=2.34 \mathrm{~Hz}\right)$. ESI-MS (m/z): $194(\mathrm{M}+1)$.

Similarly, 3,4-dihydro-3-(2'-hydroxyethylene)-6-ethyl-2H-benzoxazine (BM2) and 3,4-dihydro-3(2'-hydroxyethylene)-6-methoxy-2H-benzoxazine (BM3) were prepared as described for BM1. The starting materials for BM2 and BM3 were 4-ethylphenol (12.22 g, $100.0 \mathrm{mmol}$ ) and 4-methoxyphenol (12.41 g, $100.0 \mathrm{mmol})$, respectively (Scheme 1).

BM2: yield 72\%; clear and yellow liquid; $\mathrm{R}_{\mathrm{f}}=0.80\left(10 \% \mathrm{MeOH}\right.$ in $\left.\mathrm{CH}_{2} \mathrm{Cl}_{2}\right)$; FTIR (ATR, ZnSe, $\mathrm{cm}^{-1}$ ): 3600-2900 (br, OH), 2954 (s, CH), 1496 (oxazine ring), 1226 (s, CN), 1126 (s, CO), 1025 (s, Ar-O-C), 825 (b, CH); ${ }^{1} \mathrm{H}$ NMR (400 MHz, $\left.\mathrm{CDCl}_{3}, \mathrm{ppm}\right): \delta_{\mathrm{H}} 1.20\left(3 \mathrm{H}, \mathrm{t}, \mathrm{Ar}_{-} \mathrm{CH}_{2} \mathbf{C H}_{3} J_{1}=7.55 \mathrm{~Hz}\right)$, $2.55\left(2 \mathrm{H}, \mathrm{q}, \mathbf{C H}_{2}-\mathrm{CH}_{3} J_{1}=7.55 \mathrm{~Hz}\right), 2.96\left(2 \mathrm{H}, \mathrm{t}, \mathbf{C H}_{2} \mathrm{CH}_{2} \mathrm{OH} J_{2}=5.18 \mathrm{~Hz}\right), 3.86\left(2 \mathrm{H}, \mathrm{t}, \mathrm{CH}_{2} \mathbf{C H}_{2} \mathrm{OH}\right.$ $\left.J_{2}=5.18 \mathrm{~Hz}\right), 4.34\left(2 \mathrm{H}, \mathrm{s}, \operatorname{Ar}-\mathbf{C H}_{2}-\mathrm{N}\right), 4.84\left(2 \mathrm{H}, \mathrm{s}, \mathrm{O}-\mathbf{C H}_{2}-\mathrm{N}\right), 6.70\left(\mathrm{H}, \mathrm{d}, \mathbf{A r}-\mathbf{H}, J_{3}=2.34 \mathrm{~Hz}\right), 6.72$. $(\mathrm{H}, \mathrm{s}, \mathbf{A r}-\mathbf{H}), 6.77$ (H, d, Ar-H, $\left.J_{3}=2.34 \mathrm{~Hz}\right)$. ESI-MS (m/z): $208(\mathrm{M}+1)$.

BM3: yield 75\%; clear and yellow liquid; $\mathrm{R}_{\mathrm{f}}=0.78\left(10 \% \mathrm{MeOH}\right.$ in $\left.\mathrm{CH}_{2} \mathrm{Cl}_{2}\right)$; FTIR (ATR, ZnSe, $\mathrm{cm}^{-1}$ ): 3600-2900 (br, OH), 2947 (s, CH), 1496 (oxazine ring), 1211 (s, CN), 1141 (s, CO), 1027 (s, Ar-O-C), 810 (b, CH); ${ }^{1} \mathrm{H}$ NMR (400 MHz, $\left.\mathrm{CDCl}_{3}, \mathrm{ppm}\right): \delta_{\mathrm{H}} 2.94\left(2 \mathrm{H}, \mathrm{t}, \mathbf{C H}_{2} \mathrm{CH}_{2} \mathrm{OH} J_{2}=4.00 \mathrm{~Hz}\right.$ ), $3.73\left(3 \mathrm{H}, \mathrm{s}, \mathbf{C H}_{3}-\mathrm{O}\right), 3.77\left(2 \mathrm{H}, \mathrm{t}, \mathrm{CH}_{2} \mathbf{C H}_{2} \mathrm{OH} J_{2}=4.00 \mathrm{~Hz}\right), 4.33\left(2 \mathrm{H}, \mathrm{s}, \operatorname{Ar}-\mathbf{C H}_{2}-\mathrm{N}\right), 4.81(2 \mathrm{H}, \mathrm{s}$, O-CH $\left.\mathbf{C H}_{2}-\mathrm{N}\right), 6.71\left(\mathrm{H}, \mathrm{d}, \mathbf{A r}-\mathbf{H}, J_{3}=3.88 \mathrm{~Hz}\right), 6.49$. (H, s, Ar-H), $6.76\left(\mathrm{H}, \mathrm{d}, \mathbf{A r}-\mathbf{H}, J_{3}=3.88 \mathrm{~Hz}\right)$. ESI-MS (m/z): $210(\mathrm{M}+1)$.

\subsection{Liquid Extraction of Alkali Metal Ions}

Alkali metal ion extractions were qualitatively and quantitatively studied with Pedersen's technique [16,17]. The benzoxazine monomers (BM1, BM2, and BM3) in methylene chloride were prepared at concentrations of $7.0 \times 10^{-2}, 7.0 \times 10^{-3}, 7.0 \times 10^{-4}$, and $7.0 \times 10^{-5} \mathrm{M}$, while the alkali metal picrates aqueous solutions $\left(\mathrm{Na}^{+}, \mathrm{K}^{+}, \mathrm{Cs}^{+}\right.$-picrates) were prepared at a concentration of $7.0 \times 10^{-5} \mathrm{M}$. Five milliliters of each solution were vigorously mixed and left at room temperature until each phase was completely separated. The absorbance of metal picrate aqueous solutions was measured by UV-Vis at $\lambda_{\max } 355.0 \mathrm{~nm}$. The percentage extraction of metal concentration was calculated by the equation $\left[\left(A_{o}-A\right) / A_{o}\right] \times 100$ where $A_{o}$ is the initial absorbance of the picrate solution, and $A$ is the absorbance of the picrate solution after extraction with the monomer. The complexes in the organic phase were collected to clarify the ion-monomer interaction by UV-Vis.

\subsection{Complexation of Benzoxazine Monomers and Ce(III) Ion}

The ethanolic solutions of $\mathrm{Ce}\left(\mathrm{NO}_{3}\right)_{3} \cdot 6 \mathrm{H}_{2} \mathrm{O}$ and benzoxazine monomer derivatives (BM1, BM2, and BM3) were individually prepared with an equimolar concentration of $7.0 \times 10^{-3} \mathrm{M}$. To investigate the complex formation, the molar ratio and the Job's methods were applied.

For the molar ratio method, a series of solutions containing $0.50 \mathrm{~mL}$ of $\mathrm{Ce}(\mathrm{III})$ ion and each benzoxazine monomer (BM1, BM2, or BM3) of different volumes (2.00, 3.00, 3.50, 4.00, 4.50, 5.00, 
$5.50,6.00,6.50,7.00,7.50,8.00,9.00,10.00$ and $11.00 \mathrm{~mL}$ ) was mixed and subsequently adjusted with ethanol to attain a total volume of $25.00 \mathrm{~mL}$.

For the Job's method, a series of mixture solutions of Ce(III) ion and each benzoxazine monomer (BM1, BM2, or BM3) with various $\mathrm{Ce}(\mathrm{III})$ ion mole fractions, $\mathrm{X}(\mathrm{X}=0.05,0.08,0.10,0.15,0.20$, $0.25,0.30,0.35,0.40,0.45,0.50,0.60,0.70$ and 0.80 ) was prepared.

The absorbance of each mixture solution was measured at $\lambda_{\max } 459.5,455.5$ and $470.0 \mathrm{~nm}$ for Ce(III)-BM1, Ce(III)-BM2, and Ce(III)-BM3, respectively.

All solutions of $\mathrm{Ce}$ (III)-benzoxazine monomer complexes were collected and dried over anhydrous sodium sulfate to eliminate water and any moisture in the solvent. The solvent was then removed by vacuum distillation to obtain the brown solid products which were collected to analyses the metal ionmonomer interaction with FTIR.

\subsection{Computational Simulation}

Molecular dynamics (MD) simulations were conducted to investigate complementary insights into Ce(III)-BM1 complex associations that abet the interpretation of experimental spectroscopic data. Molecular dynamics simulations were performed with the Forcite module in the Accelrys Inc Materials Studio (version 5.5) [21]. The all-atom, force-field, Universal force field was used to perform simulations of the cerium interactions of metal cations with $\mathrm{O}$ and $\mathrm{N}$ positions of BM1 ligand, whereby the force field was used to describe all atoms in the simulated systems, including those of cerium metal cations [22-25]. Universal is moderately accurate for predicting geometries and conformational energy differences of organic molecules, main-group inorganics, and metal complexes. It is recommended for organometallic systems and other systems for which other force fields do not have parameters. The energy minimization and annealing MD simulations were performed to push the system into a global energy minimum, followed by a final MD step from which energy and structural data were retrieved after examination of the total potential energy as a function of time indicated equilibration. This final MD step was carried out in the canonical ensemble (constant number of atoms $(\mathrm{N})$, simulation cell volume $(\mathrm{V})$, and temperature $(\mathrm{T})$ ) for up to 60 picoseconds (ps) (time step 1.0 femtoseconds [fs]) using a canonical thermostat algorithm to control temperature at $298 \mathrm{~K}$.

\subsection{Preparation of Ceria ( $\left.\mathrm{CeO}_{2}\right)$ from Ce(III)-Benzoxazine Monomer Complexes}

To obtain $\mathrm{CeO}_{2}$ powders, all complex products were calcined in alumina crucibles at $600{ }^{\circ} \mathrm{C}$ for $2 \mathrm{~h}$ [19]. The powders obtained were studied by XRD for phase identification and TEM for morphology observation.

\section{Conclusions}

The present work shows that benzoxazine monomers provide ion extraction properties for various ions via their molecular assembly. None of the benzoxazine monomers with different substituted groups on the phenolic moiety showed significant differences in ion extraction ability and no ion selectivity was observed. This might be due to a loose and flexible structure formation of the molecular assembly, which leads to high capability and selectivity with ion interaction. 
This study also revealed that all of the proposed benzoxazine monomers show properties as novel ligands for the Ce(III) ion. With the molar ratio and Job's methods, the metal-ligand ratios between the Ce(III) ion and the benzoxazine monomers (BM1, BM2, and BM3) in ethanolic solution were found to be 1 to 6 . A possible structure of Ce(III)-BM1 complex based on molecular dynamics simulations was proposed and found to be in agreement with the FTIR results.

Pure ceria nanoparticles were successfully prepared from the complexes of Ce(III)-benzoxazine monomers by calcinating at $600{ }^{\circ} \mathrm{C}$ for $2 \mathrm{~h}$. The obtained particles were spherical with an approximate size of 10-20 nm. By the application of the aforementioned method, diverse advantages are evident, such as a simple reaction which occurs in the absence of specific solvents at room temperature. Additionally, high surface area ceria are obtained as compared with previous ligands like triethanolamine and benzoxazine dimer [18-20]. We plan to use the so obtained ceria nanoparticles as the solid support for metal catalysts in further studies by our research group.

\section{Acknowledgments}

The authors would like to acknowledge the financial support from The Joint Research Program of the National Research Council of Thailand (NRCT) and the Japan Society for the Promotion of Science (JSPS), Kasetsart University Research and Development Institute (KURDI) and the Center of Advanced Studies in Industrial Technology, Faculty of Engineering, Kasetsart University. Appreciation is also expressed to Suwabun Chirachanchai, The Petroleum and Petrochemical College, Thailand and Hitachi Hi-Technologies Corporation, Japan for TEM observation.

\section{References and Notes}

1. Steed, J.W.; Atwood, J.L. Supramolecular Chemistry; John Wiley \& Sons, Ltd.: Chichester, UK, 2000; p. 116.

2. Arduni, A.; Pochini, A.; Reverberi, S.; Ungaro, R. The preparation and properties of a new lipophilic sodium selective ether ester ligand derived from $p$-t-butylcalix[4]arene. Tetrahedron 1986, 42, 2089-2100.

3. Böhmer, V. Calixarenes, macrocycles with (almost) unlimited possibilities. Angrew. Chem. Int. Ed. Engl. 1995, 34, 713-745.

4. Sone, T.; Ohba, Y.; Yamazaki, H. Inclusion Properties of Acyclic p-Substituted PhenolFormaldehyde Oligomers. Bull. Chem. Soc. Jpn. 1989, 62, 1111.

5. Yamagishi, T.; Tani, K.; Ishida, S.; Nakamoto, Y. Linear all-ortho oligomers of phenolformaldehyde resins. Polym. Bull. 1994, 33, 281.

6. Chirachanchai, S.; Laobuthee, A.; Phongtamrug, S.; Siripattanasarakit, W.; Ishida, H. A novel ion extraction material using host-guest properties of oligobenzoxazine local structure and benzoxazine monomer molecular assembly. J. Appl. Polym. Sci. 2000, 77, 2561.

7. Laobuthee, A.; Chirachanchai, S.; Ishida, H.; Tashiro, K. Asymmetric Mono-oxazine: An Inevitable Product from Mannich Reaction of Benzoxazine Dimers. J. Am. Chem. Soc. 2001, 123, 9947. 
8. Laobuthee, A.; Chirachanchai, S. A simple, effective, and selective synthesis route for difunctional 30-membered macrocyclic ester and linear oligoester derived from benzoxazine dimers. Chem. Lett. 2002, 6, 613-614.

9. Chirachanchai, S.; Phongtamrug, S.; Laobuthee, A. A simple, effective, and selective synthesis route without template effect (part II) for [2 +2] difunctional 28-membered macrocyclic ethers based on benzoxazine dimers and its inclusion phenomena with metal ions. Chem. Lett. 2003, 5, 432-433.

10. Laobuthee, A.; Ishida, H.; Chirachanchai, S. Metal ion guest responsive benzoxazine dimers and inclusion phenomena of cyclic derivatives. J. Incl. Phenom. Macrocycl. Chem. 2003, 47, 179-185.

11. Chirachanchai, S.; Rungsimanon, T.; Phongtamrag, S.; Miyata, M.; Laobuthee, A. Selective Macrocyclization: A Model Case Study from N,N-bis(2-hydroxy-3,5-dimethylbenzyl)alkylamine. Tetrahedron 2009, 65, 5855-5861.

12. Chirachanchai, S.; Laobuthee, A.; Phongtamrag, S. Self termination of ring opening reaction of $p$-substituted phenol-based benzoxazines: An obstructive effect via intramolecular hydrogen bond. J. Heterocycl. Chem. 2009, 46, 714-721.

13. Kaewvilai, A.; Rungsimanon, T.; Koonsaeng, N.; Chirachanchai, S.; Laobuthee, A. Branching structures of alkali metal ion responsive supramolecules based on symmetric structures of N,N-bis(5-alkyl-2-hydroxybenzyl)methylamine. Asian J. Chem. 2010, 22, 7628-7640.

14. Holly, F.W.; Cope, A.C. Condensation Products of Aldehydes and Ketones with o-Aminobenzyl Alcohol and o-Hydroxybenzylamine. J. Am. Chem. Soc. 1944, 66, 1875.

15. Phongtamrug, S. Study on the benzoxazine monomers and their application for ion extraction material. Master Degree Thesis in Polymer Science; The Petroleum and Petrochemical College, Chulalongkorn University: Bangkok, Thailand, 1998.

16. Pedersen, C.J. Cyclic Polyesters and Their Complexes with Metal Salts. J. Am. Chem. Soc. 1967, 89, 1009-1020.

17. Pedersen, C.J.; Frensdorff, H.K. Macrocyclic polyethers and their complexes. Angew. Chem. Int. Ed. Engl. 1972, 11, 16.

18. Rakthin, T.; Veranitisagul, C.; Koonsaeng, N.; Traversa, E.; Laobuthee, A. Preparation of Ceria Powder via Metal-Organic Complex Method. In Proceedings of Pure and Applied Chemistry International Conference: Chemistry for Sufficiency and Sustainability, Amsterdam, The Netherlands, 22-23 February 2008; Parasuk, W., Ed.; Chemical Society of Thailand: Bangkok, Thailand, 2008; pp. 312-316.

19. Veranitisagul, C.; Kaewvilai, A.; Sangngern, S.; Wattanathana, W.; Suramitr, S.; Koonsaeng, N.; Laobuthee, A. Novel Recovery of Nano-Structured Ceria $\left(\mathrm{CeO}_{2}\right)$ from $\mathrm{Ce}(\mathrm{III})-\mathrm{Benzoxazine}$ Dimer Complexes via Thermal Decomposition. Int. J. Mol. Sci. 2011, 12, 4365-4377.

20. Wattanathana, W.; Lakkham, A.; Kaewvilai, A.; Koonsaeng, N.; Laobuthee, A.; and Veranitisagul, C. Preliminary Study of $\mathrm{Pd} / \mathrm{CeO}_{2}$ Derived from Cerium Complexes as Solid Support Catalysts for Hydrogenations Reaction in a Micro-reactor. Energy Procedia 2011, 9, 568-574.

21. Accelrys Inc Materials Studio 5.5. Accelrys: San Diego, CA, USA. 
22. Rappé, A.K.; Casewit, C.J.; Colwell, K.S.; Goddard, W.A.; Skiff, W.M. UFF, A Rule-Based Full Periodic Table Force Field for Molecular Mechanics and Molecular Dynamics Simulations. J. Am. Chem. Soc. 1992, 114, 10024.

23. Rappé, A.K.; Colwell, K.S.; Casewit, C.J. Application of a Universal Force Field to Metallic Complexes. Inorg. Chem. 1993, 32, 3438.

24. Rappé, A.K.; Goddard, W.A. Charge equilibration for molecular dynamics simulations. J. Phys. Chem. 1991, 95, 3358-3363.

25. Casewit, C.J.; Colwell, K.S.; Rappé, A.K. Application of a Universal Force Field to Organic Molecules. J. Am. Chem. Soc. 1992, 114, 10035.

Sample Availability: Samples of the compounds BM are available from the authors.

(C) 2012 by the authors; licensee MDPI, Basel, Switzerland. This article is an open access article distributed under the terms and conditions of the Creative Commons Attribution License (http://creativecommons.org/licenses/by/3.0/). 